\title{
DE LOBOS Y DE FAUCES: \\ EL CONOCIMIENTO SOCIO-HISTÓRICO EN EL FIN DE SIGLO
}

\author{
POR \\ MARISA GONZÁLEZ DE OLEAGA \\ Instituto Universitario Ortega y Gasset \\ Madrid
}

La crisis abierta en ciencias sociales ha afectado de manera particular al conocimiento socio-histórico, vaciándole de sentido. Esta ruptura se ha visto acompañada de la aparición de nuevas y dispersas prácticas historiográficas. Las líneas que siguen pretenden ser un avance de una propuesta de mayor alcance que persigue, partiendo de una particular interpretación de la crisis, dotar de nueva capacidad crítica al saber histórico.

(...) Estos hechos y muchos otros persuaden de cuán irrisorio es querer objetar nuestra sociedad sin pensar jamás los límites mismos de la lengua mediante la cual pretendemos objetarla: es querer destruir al lobo alojándose confortablemente en sus fauces ( $R$. Barthes).

Tan tierra son que son ellos la tierra andando con los huesos de sus muertos (A. Roa Bastos)

Avance de un estudio de mayor envergadura que se inscribe dentro del Proyecto de I+D SEC94-0196 del Ministerio de Educación y Ciencia. 


\section{EL PROBLEMA: «MOMENTOS DE VERDAD» $Y$ CONOCIMIENTO HISTÓRICO $\left(^{*}\right)$}

En los últimos tiempos hemos asistido a un doble proceso en el campo de las Ciencias Sociales. Por un lado, a una pérdida relativa de la capacidad crítica y directiva del conocimiento histórico al tiempo que a una revalorización del pasado, entendida en términos estrictamente estéticos o museísticos, la moda "nostalgia» de la que, acertadamente habló Frederic Jameson (1). En este contexto hay que inscribir el éxito obtenido por la novela histórica, entendida como un género que, entre otras cosas, recrea o especula libre y deliberadamente sobre lo acontecido. Por otro, esta paradoja de «hiperhistorización sin historia» se ha visto acompañada de un creciente interés, particularmente en el caso de la historiografía, pero seguramente extensible a otros saberes, por los fenómenos de naturaleza política. Lo político y de forma especial los procesos de construcción de las democracias o, en el caso de la Ciencia Política y la Sociología, las transiciones desde regímenes autoritarios han concitado un particular interés, tanto académico como social.

En el reconocimiento de la pérdida de capacidad crítica del saber histórico, entendido como "guía para la acción», tuvo algo que ver -menos, seguramente, de lo que el autor

$\left.{ }^{*}\right)$ Este trabajo surge con bastantes particularidades. Entre ellas, la de haber sido escrito después de ser difundido y comentado con colegas y alumnos de cuyas interpelaciones evidentemente se ha beneficiado. Por ello quiero hacer llegar mi reconocimiento, en primer lugar, al profesor Antonio Niño, crítico implacable y buen amigo que se tomó la molestia de leer otros borradores y de hacer sugerentes y agudas anotaciones y comentarios. A la profesora E. Hernández Sandoica quien tuvo la amabilidad de leer otra de las versiones y de animarme en este cometido del que ella tiene un profundo conocimiento. En el seminario que dirige la profesorá Marta Casaus en la Universidad Autonóma encontré excelentes interlocutores entre docentes y alumnos: la doctora Teresa García Giraldez y los asiduos asistentes a la reunión. Por último, vaya mi agradecimiento a los alumnos que en los tres últimos años han participado, con paciencia y entusiasmo, en el curso de doctorado que, conjuntamente con el profesor Niño, imparto en la Facultad de Geografía e Historia de la Universidad Complutense.

(1) Frederic JAMESON, El posmodernismo o la lógica cultural del capitalismo avanzado. Barcelona, Paidós, 1995, págs. 46-52. También Gilles Lipovestky ha hecho hincapié en este fenómeno.

R. I., 1996, n. ${ }^{\circ} 207$ 
norteamericano admitiría y mucho más de lo que el gremio estaría dispuesto a concederle- la aparición del ya famoso libro de Francis Fukuyama, El fin de la Historia. Su influencia no está relacionada con la calidad de la obra, pero tampoco se ciñe -como señala Fontana en su no menos famoso libro $\mathrm{La}$ Historia después del fin de la historia- a la buena campaña de mercadotecnia que apoyó su difusión. Una mala obra como ésta puede provocar un amplio debate gracias a la oportunidad de su aparición y a su capacidad para formular o verbalizar los contenidos de una crisis latente. De hecho el impacto del trabajo de Fukuyama queda reflejado en el título del libro de Fontana.

El fin de la historia en su sentido evolutivo y su correlato, el fin de una forma de entender y aplicar el saber histórico, han provocado toda suerte de reacciones. Además estos nuevos aires han venido soplando bajo las banderas de una «nueva historia política", con lo cual no fueron pocos los que creyeron y que aún creen estar en presencia de un resurgimiento de la vieja historiografía empirista. Por si fuera poco, a los más informados les llegaban voces, del otro lado de los Pirineos, que proclamaban la fragmentación del sujeto, que pretendían reducir la realidad a un conjunto de textos y que negaban algo tan aparentemente esencial en el trabajo de los historiadores como es la existencia de la realidad como referente externo.

Ante semejante colapso, se dividieron las aguas y los pescadores entre aquellos que siguieron negando la existencia de crisis alguna y encerrados en sus quehaceres, y por aquello del "publish or perish», continuaron como lo habían hecho hasta entonces, y los que, convencidos de la maldad intrínseca de los tiempos que corren -manifiesta en el rebrote de la historia política o en los relativismos de todo orden-, han jurado vencer al enemigo mediante el atrincheramiento en los presupuestos de una historia militante a la vieja usanza. Sería faltar a la verdad si no dijera que otros, los menos (2), han intentado otras posi-

(2) En los últimos meses han aparecido dos textos sobre metodología de la historia elaborados por dos conocidos y reconocidos historiadores que, a través de su trabajo docente e investigador, han mostrado especial interés por estas cuestiones. Me refiero al libro de la profesora Elena HeRNÁNDEZ SANDOICA, Los caminos de la historia. Madrid, Síntesis, 1995 y el del 
bilidades. Aquellos que, partiendo de un análisis de la crisis, han intentado reconducir o adecuar su trabajo. Entre estos últimos -en una suerte de camino intermedio- pretende estar la propuesta que presentaré a lo largo de estas páginas.

Bien es cierto que hubo mejores tiempos para el conocimiento socio-histórico. Tiempos en los que su utilidad social parecía incuestionable aunque no estoy tan segura de que esa certeza nos llevara a buen puerto, a tenor de nuestra situación actual. En todo caso, esos tiempos han pasado y los nuevos exigen la construcción de nuevas utilidades, de nuevas funcionalidades para ese conocimiento. Lo que ha entrado en crisis no es el saber histórico sino una forma de construirlo y de utilizarlo. La historia no ha perdido su potencial capacidad crítica, lo que pasa es que los nuevos tiempos exigen nuevas potencialidades, la construcción de nuevas formas de escribir la historia más acorde con las necesidades sociales y con las distintas formas de concebir lo humano y lo social. Resulta, cuando menos paradójico, que sean los historiadores y la historiografía, los que nieguen el carácter cambiante de la funcionalidad del discurso histórico. Ampararse en la negación de la crisis, o atrincherarse en las viejas fórmulas no hará sino ahondar en la desconexión entre conocimiento histórico y necesidades sociales, profundizando aún más en el carácter fútil del saber, vaciándolo de sentido. De tal forma que resulta imperativo interpretar la crisis, deducir de ella su posible carácter y profundidad para intentar extraer de ese análisis su potencialidad crítica. No puedo por menos que reccger aquí la sentencia de Marx que recrea F. Jameson al hablar de los "momentos de verdad" y según la cual hay que hacer lo imposible por pensar la realidad en términos positivos y negativos, por llevar nuestro pensamiento hasta ese umbral que nos permita ver y comprender cuánto hay de dinámica emancipadora en la realidad por muy denigrante que ésta parezca o sea (3).

En este contexto, la revalorización de lo político o en sentido más amplio los reclamos en favor de la historia ficción -otra

profesor Julio ARóstegui, La investigación histórica: teoría y método. Barcelona, Crítica, 1995.

(3) Es esta una versión libre de lo que Jameson, parafraseando a Marx, expone en su libro sobre la posmodernidad. Véase Frederic JAMESON [1].

R. I., 1996, n. 207 
forma de entender la historia posible- son fenómenos interesantes, un campo de problemas privilegiado por esa demanda social que exige un tipo de conocimiento histórico útil. Evidentemente esto no es ninguna garantía. La demanda social puede existir y no necesariamente ser satisfecha por la producción historiográfica, sobre todo si los productores se empeñan en no valorar la crisis, en no interpretarla o en no adecuar su trabajo a las preguntas o a las exigencias actuales. Ahora bien, suponiendo que se acepta lo dicho y que la aparente paradoja de «la hiperhistorización sin historia» y, dentro de ella, la revalorización del conocimiento de lo político pueda salvarse a través de una adecuación entre necesidades sociales y producción historiográfica -amparada en una nueva filosofía de la historia-, ¿cuáles son esas necesidades?, ¿cómo definirlas?, ¿cuáles serán los criterios de pertinencia con los que evaluar la virtualidad comprensiva de la nueva historigorafía?, ¿cómo han de condicionar la práctica de los historiadores esos criterios a la hora de formular problemas, de elegir marcos de análisis, de fragmentar el propio campo de estudio?, ¿cuáles han de ser los objetivos de la historiografía crítica ante la crisis del empirismo y del determinismo?, ces posible construir nuevos propósitos para esa historiografía que se podría reclamar, por que no, heredera de la tradición del optimismo militante? (4).

De algunos de estos aspectos se ocuparán las páginas que siguen. La propuesta que se esbozará a continuación no pretende ser el trazo rápido de una nueva filosofía de la historia y ello no sólo por humildad personal sino porque a juicio de quien esto escribe los nuevos tiempos requieren, en el mejor de los casos, de programas parciales y coyunturales, de pistas que, a través de una posible -entre otras-interpretación del momento actual, nos habiliten para reintegrar nuestras prácticas, para darles sentido; un sentido que vaya más allá de nuestras miserias cotidianas.

En la búsqueda de esa nueva trascendentalidad con frecuencia me he tropezado con colegas asombrados, cuando no dis-

(4) Optimismo militante a la manera definida por Ernest BLOCH, «(...) la actitud ante ese algo no-decidido, pero decidible por el trabajo y la acción inmediata (...)" en "Optimismo militante: las categorías 'frente', 'novum', 'ultimun'» de El principio esperanza, t. I, Salamanca, Sígueme, 1972, págs. 190-197. 
gustados, por tal pretensión. ¿Por qué habrían de buscarse objetivos al conocimiento socio-histórico? Alguno de estos eventuales interlocutores postulaban que los historiadores tienen, como individuos, sus propios cometidos y que, como gremio, les guía la idea de verdad y que la búsqueda de funciones no dejaba de ser un resabio autoritario basado en la presunta función liberadora del saber histórico. Por ello, quiero adelantar algunas consideraciones en este sentido. En primer lugar, que la propuesta que sigue no pretende ser un artículo de fe con el que deban comulgar los historiadores individuales con sus confesables e inconfesables intenciones. No estoy hablando de los individuos sino del conocimiento socio-histórico como saber potencialmente útil, las inclinaciones personales podrían ser útiles para una psicología del historiador, pero no para la presente propuesta. En segundo, nunca conseguí entender muy bien por qué al plantear sugerencias que de lejos podían rozar la idea del conocimiento como liberación se tildaba a su portador o proponente de autoritario, partidario de modelos totalitarios y otros epítetos similares.

Existe una confusión en torno a este problema al considerar que la idea de conocimiento útil y su capacidad liberadora es propiedad de un único modelo filosófico e ideológico y de un modelo político que tuvo su correspondiente encarnación durante este siglo. Señalar que el conocimiento socio-histórico ha de ser un conocimiento socialmente útil no implica aceptar una imagen particular de futuro basada en un sujeto único ni creer que su anticipación se basará en el conocimiento de las grandes tendencias que rigen la vida social. Potenciar la capacidad crítica del saber histórico no nos vuelve ni deterministas ni autoritarios, entre otras cosas porque ese conocimiento puede ser liberador -en términos de autoconsciencia de los sujetos, de apertura hacia la relatividad de su propia existencia- gracias a su potencial reflexivo, a su capacidad de dar cuenta de la posibilidad en torno a una multiplicidad de sujetos e identidades.

El conocimiento socio-histórico y el discurso historiográfico que le es propio han sido objeto de apropiación social y política a lo largo de la historia. A la pregunta de ipor qué habríamos de buscar funciones al conocimiento socio-histórico? la respuesta podría ser: porque las tiene y el escamoteo de su po- 
tencial función crítica -entendida en su sentido más ampliono deja de ser una forma de apropiación social y política que puede tener repercusiones en la acción colectiva. Defender la posibilidad de construcción de un saber socialmente útil no nos sitúa ante ninguna nueva utopía universal sino que nos habilita para pensar en la posibilidad de entrever alternativas futuras a través de la acción de los sujetos.

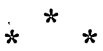

Pero volviendo al argumento central de este relato, según el cual nos hayamos en un momento paradójico en el que se produce un vaciamiento de la función crítica del saber histórico al tiempo que una revalorización de los fenómenos políticos, se han indicado tres piezas como partes del rompecabezas: crisis, propuestas y práctica.

Por un lado, se señaló la existencia de una crisis de descorrelación o desencuentro entre una forma de construir el discurso historiográfico y la tendencia de la demanda social en el sentido de un saber socialmente útil. Se partía de la premisa, si no se dijo aprovecho ahora para hacerlo, de que esa crisis era y es insoslayable. Independientemente de la interpretación que quiera dársele la fractura está ahí y obedece a un doble proceso: político y epistemológico, del que nos ocuparemos en el segundo epígrafe.

De esa caracterización, siempre provisional, de la crisis dependerán en buena parte los atisbos de solución. Un sector de la historiografía ha condenado las nuevas prácticas historiográficas -ligadas a la antropología, al giro lingüístico, a las propuestas de $\mathrm{H}$. White o a unidades de análisis micro- por considerarlas como fundadoras de una nueva racionalidad acrítica que ha viciado la utilidad del conocimiento histórico. Desde mi perspectiva el problema no está en las prácticas -que evidentemente si bien no son sólo producto sí están relacionadas con un contexto social y político- sino en la posibilidad de producir, a través de esas prácticas que reflejan una necesidad, un tipo de conocimiento útil para los sujetos sociales. Para ello se hace necesario establecer ciertos criterios de pertinencia generales que, derivados de la conceptualización de la crisis y de la interpretación de nuestras necesidades más 
generales, puedan sugerir o dibujar itinerarios historiográficos. De todo ello se dará cuenta en el tercer epígrafe, el de la propuesta, en el que, además se intentará definir a muy grandes rasgos los nuevos objetivos de una historiografía crítica que pretenda ser postempirista y postdeterminista, esto es, que pretenda soldar la fractura entre saber y sociedad.

Por último, cerraré el texto con una breve anotación sobre la forma en que esta propuesta puede afectar nuestra práctica en términos de elección de temas, formulación de problemas, formas de razonamiento y otros aspectos que, generalmente, se consideran como los propiamente historiográficos.

No quiero dar por finalizada esta larga introducción sin hacer mención, siquiera de pasada, a algunas ideas que a modo de auto-objeción me han estado hostigando y que prometen seguir haciéndolo durante la redacción de estas páginas. Se que resulta osado especular sobre un tema como el propuesto y más aún sobre rudimentarias filosofías de la historia. La historiografía con demasiada frecuencia debate sobre hechos y acontecimientos olvidando su responsabilidad en la construcción de conocimiento, toda vez que la acción humana parece estar relacionada y condicionada por esa construcción. Por ello, y a pesar de la osadía de la que me acuso, es ésta una invitación a reflexionar sobre la práctica historiográfica con alguna pretensión más que la derivada de la constatación o refutación de los hechos que atañen al trabajo de cada cual. Si, como señala Barthes, es inútil intentar mantener, siquiera, una postura crítica respecto a nuestra realidad inmediata sin tomar en consideración los límites que imponen nuestros instrumentos de análisis, el discurso historiográfico -enraizado en prácticas y formas de razonamiento históricas que no naturales- es uno de los umbrales desde el que cuestionar esa cotidianidad. Umbral, horizonte significativo porque desde su categoría de discurso de la experiencia, depósito de saberes colectivos, puede inspirar las prácticas sociales. De cómo repensar el lobo evitando caer en la tentación de instalarse cómodamente en sus fauces darán cuenta las páginas que siguen y en este sentido deben ser entendidas estas líneas.

R. I., 1996, n.o 207 


\section{LA CRISIS: BUSCANDO PISTAS ENTRE LA EPISTEMOLOGÍA Y LA POLÍTICA}

La crisis de pérdida de sentido del conocimiento histórico es, en buena medida, producto de la aparición de nuevas necesidades colectivas y de nuevas formas de entender el devenir humano y social. Se ha producido un desencuentro entre los viejos paradigmas historiográficos, -asentados en concepciones más o menos concretas sobre la naturaleza humana, la instrumentalidad del saber histórico o sobre los contenidos de la utopía mundial en cuya construcción debía participar como disciplina rectora el conocimiento del pasado- y las exigencias sociales. Pero esa ruptura en el sentido del saber histórico se ha visto acompañado de una hiperhistorización de la vida cotidiana y de una revalorización de la historiografía política. Ahora bien, el creciente interés social y académico por los fenómenos de esa naturaleza (5) ha sabido discriminar algunos problemas frente a otros: los orígenes y las transiciones a la democracia, esto es, los procesos relacionados con las formas de organización de la vida política son los que, de forma notoria (6), han concentrado el interés general.

(5) Buena prueba de ello son las nuevas líneas de investigación abiertas, -en las que se inscribe el proyecto de investigación que ha financiado este trabajo: proyecto de I+D SEC94-0196 concedido por el Ministerio de Educación y Ciencia-, o la reaparición de la historia política en los currícula académicos.

(6) La convocatoria de congresos internacionales en los que se prioriza la temática política -como el celebrado en octubre de 1995 en Colombia bajo el lema la formación de la ciudadania en América Latina por citar tan sólo un ejemplo-, o la composición de las mesas dedicadas a estos temas en encuentros nacionales o internacionales avalan esta afirmación. Por ejemplo en el último congreso de la Latin American Studies Association, celebrado en Washington en septiembre de 1995, el proceso de revalorización se ha hecho notar. De las diez Sesiones Plenarias cinco abordaron temas específicamente políticos y de las Sesiones Especiales, veinte en total, más de la mitad de las ponencias -once- se centraron en esta temática. En uno y otro caso las sesiones restantes se caracterizaron por la dispersión temática, no consiguiendo aglutinar ningún campo específifico; o en el $V$ Congreso de Latinoamericanistas españoles, que tuvo lugar en Sevilla en noviembre de 1995, en donde dos de las trece mesas han tenido el cometido de abordar los problemas relacionados con la construcción del orden republicano y con la consolidación de las democracias en América Latina, fenómenos ambos de clara naturaleza política. 
En el contexto de este trabajo, la revalorización de lo político se ha singularizado, en relación con la pérdida de sentido del saber historiográfico, como un aspecto importante de la paradoja de la «hiperhistorización sin historia» que relativiza la crisis y que permite, en la medida que responde a una demanda social, volver a soldar esa relación que puede hacer del conocimiento histórico un saber socialmente útil. Por ello es desde este aspecto y no desde otros desde donde se va a interpretar la crisis de sentido, que, por otra parte, y como si se tratase de un caleidoscopio, tiene múltiples derivaciones.

No resulta difícil establecer cierta relación entre este proceso de revalorización de lo político y las necesidades sociales y colectivas abiertas en el cambio de siglo. Dos son las razones, entre otras, que lo hacen inteligible. Por un lado, los desafíos impuestos desde distintos flancos a la, de por sí, ardua tarea de pensar y articular modelos de convivencia colectiva. Por otro, nuevas formas de concebir la realidad en general y la realidad social en particular.

Tanto en Europa como en América Latina se han sucedido una serie de procesos que han cuestionado seriamente los conceptos de representatividad y legitimidad democráticas. Las transiciones políticas en los países lationoamericanos y en los países del Este, los movimientos migratorios en el sentido SurNorte, las constantes acusaciones de corrupción de la clase política, la aparición de nuevos sujetos sociales con nuevas e inesperadas demandas - caso de las mujeres, los indígenas, los homosexuales, etc...- parecen indicar que nuestra forma de organización política colectiva necesita ser revisada.

Las transiciones a la democracia en América Latina y el colapso de los regímenes comunistas -ambos procesos en contextos económicos poco favorables que, además tienden a hacerse cada vez menos favorables, dotándoles de escasos márgenes de maniobra-, la inexistencia de modelos económicos alternativos que puedan no sólo imprimir cierta esperanza sino dictar las posibles medidas a seguir han provocado el interés de los especialistas por las instituciones y su funcionamiento y por las formas de canalizar el conflicto en escenarios que se prevén de fuerte polarización social y económica (7).

(7) Esta es una sugerencia hecha por E. Ibáñez Rojo que tuvo la amabilidad de compartirla y discutirla conmigo.

R. I., 1996, n. 207 
Por su parte las corrientes migratorias y la tendencia creciente de los desplazamientos humanos desde las periferias hacia los países desarrollados han provocado confrontaciones entre los valores portados por los inmigrantes y los sostenidos por las sociedades receptoras, de las que sucesos como el de la pertinencia o no de que las niñas musulmanas vayan con chador -o con cualquier otro signo de identificación religiosa- a la escuela en Francia es sólo un ejemplo de los muchos que se sucederán en el futuro (8).

Los procesos abiertos en Italia, Francia y España, por citar sólo algunos casos, a importantes personajes políticos relacionados con toda suerte de corruptelas han afectado a la credibilidad de las instituciones políticas y de sus representantes. Otro tanto podría decirse de América Latina donde además la corrupción, que casi ha permeado todos los espacios, parece estar sostenida por una cultura política -enraizada en concepciones patrimoniales- que la legitima.

$\mathrm{Ni}$ qué decir que uno de los mayores retos a los que ha de enfrentarse el modelo de democracia, tal y como lo consideramos hoy, proviene de otro fenómeno ligado a la aparición de nuevos sujetos sociales. Reivindicaciones como las mantenidas por las mujeres en relación a la sentencia del Tribunal de Luxemburgo contra la discriminación positiva y la política de cuotas, las affirmative actions como estrategia en favor de la

(8) El problema de las migraciones ha dado lugar a un nuevo fenómeno objeto de estudio, el de la multiculturalidad. La bibliografía sobre este tema es profusa y muy rica, tanto de parte de aquéllos que abogan por nuevas soluciones como de los que se acogen a la superioridad de los valores occidentales. Baste citar los trabajos de Julia Kristeva, Charles Taylor, Alain Touraine, Anthony Smith, Daniel Bell, Peter Brooks, Nancy Fraser y Alain Finkelkraut, entre otros. Revista de Occidente ha dedicado algunos números a esta problemática. Pueden consultarse los números 161 (coordinado por Mónica QuiJADA) de octubre de 1994; 169 de junio de 1995 y el dedicado a la polémica intercultural en los Estados Unidos de octubre de 1995. A. TouRAI$\mathrm{NE}$ acaba de publicar un muy sugerente artículo con el no menos sugerente título de "¿Qué es el multiculturalismo?" en Claves, n. 56 de octubre de 1995; y del mismo autor, «¿Desintegración política en Francia?», El País, 25-10-1995, pág. 12. En torno al problema específico de las migraciones en España ha aparecido una reciente publicación, editada por el profesor Emilio LAMo DE EsPINOSA, Cultura, Estado, Cuidadanos. Una aproximación al multiculturalismo en Europa, Madrid, Alianza, 1995. 
igualdad de las minorías o de los considerados como diferentes (por razón de sexo, raza, religión u orientación sexual), indican la inquietud de amplios sectores de la opinión pública ante las estrecheces de la democracia y cuestionan ciertos criterios básicos como la representatividad o la legitimidad del sistema y de sus instituciones.

La propia idea de «democracia territorial» según la cual sólo los nacidos, nacionalizados o residentes -aquellos a los que una instancia superior les concede atribuciones- en el territorio tienen derecho a participar políticamente y son sujetos de ese derecho que parece haberse constituido en un $a$ priori o haberse naturalizado de tal forma que no ha sido sometida a debate ni siquiera en países como los EEUU donde la población mexicana inmigrante temporal -seis meses en cada país- forma una parte importante de los contingentes.

Dentro de la aparición de nuevos sujetos sociales, los sucesos de Chiapas representan una nueva exigencia de las comunidades indígenas a su incorporación social y política y al reconocimiento de sus peculiaridades culturales, sin perjuicio de que el levantamiento haya tenido otros significados (9). En otro

(9) El levantamiento se ha constituido como un desafío a las prácticas y a la dinámica del Partido-Estado pero, no puede escapársenos, que estos indígenas reclaman, junto con otras peticiones, respecto a sus propias tradiciones. Sea ésta una estrategia oportunista o no destinada a sensibilizar a la opinión pública internacional, impulsada por el subcomandante Marcos o por cualquiera otro ideólogo (¿de raza caucásica?) ajeno al mundo indígena, lo cierto es que esta demanda ha sido asumida por los indígenas chiapanecos. Si éstos han sido engañados o no, al reivindicar el respeto a su identidad, es difícil de saber pero, en todo caso, sería igualmente difícil saber hasta que punto, si reivindicasen una incorporación plena al modelo de vida occidental abandonando sus formas tradicionales de existencia, no estarían siendo traicionados por unas expectativas irrealizables. En todo caso su reclamo de ser respetados es una reivindicación que debería tomarse muy en cuenta en América Latina. En primer lugar, porque proviene de interlocutores legítimos (no hay porqué suponer a priori que la lógica de un grupo indígena está más condicionada o es menos racional y legítima que la de cualquier otro actor) y, en segundo, por que lo mejor es lo posible. Hoy por hoy en América Latina, y hasta donde la escasa e imperfecta capacidad humana puede prever, no existen indicios de una posible integración económica y social de las minorías indígenas que, a través de los distintos procesos de socialización política que en su día conllevó esa incorporación, les puedan asegurar su participación política como portadores de los valores ciudadanos ocidentales. Antes bien, la tónica general tiende más a la

R. I., 1996, n.o 207 
orden de cosas, pero como prueba de los conflictos y retos que la aparición de nuevos sujetos sociales supondrá para las actuales estructuras estatales y nacionales, están los contenciosos que aparecen diariamente en la prensa sobre litigios protagonizados por familias-grupos religiosos contra el Estado por la titularidad en las decisiones sobre salud o educación de menores. Para terminar este rápido y nada exhaustivo recuento de los acontecimientos que han supuesto un desafío a las formas colectivas de organización política basta mencionar las salidas cívico-militares que, en potencia o acto, han intentado solucionar las disfunciones democráticas y que han contado con amplio consenso. Tal es el caso del golpe de Fujimori -ejemplo que goza de buena salud- o de los rumores, que en su día, circularon por Colombia o México.

La revalorización de los fenómenos políticos es un reflejo no intencionado de las situaciones aludidas y una búsqueda deliberada de claves con las que hacer frente a los desafíos que imponen los patrones que rigen nuestra vida colectiva. Se puede decir, y pocos se atreverían a dudarlo, que en términos políticos, el gran problema de fin de siglo está marcado por la creación de un nuevo concepto de ciudadanía y del desarrollo de las instituciones democráticas. Porque son las actuales necesidades en el sentido de construir un concepto de ciudadano que atienda a la diversidad cultural y a los diferentes reclamos las que han propiciado la necesidad de este proceso. El reto actual consiste en reformular esa noción, la del ciudadano, intentando dar cabida a la diferencia en un proceso inverso al seguido por la construcción de la ciudadanía en sus orígenes. Entonces se trató -en el caso de la América Latina del xIX y del $\mathrm{xx}$ - de un único proceso de idealización de las características de ese nuevo sujeto político al que debían

expulsión que a la integración como demuestran las cifras de informales en la ciudad de Lima y en otras urbes latinoamericanas. De lo que se trata entonces es de articular formas de participación política regidas por principios de legitimidad revisables y consensuados sustentados en formas de vida más o menos tradicionales. Respecto a Chiapas puede consultarse la abuntante bibliografía que aparece en el último artículo de Pedro PÉREZ HERRERO, "Chiapas: ¿́revolución, guerrilla, movimiento indio o reclamación de democracia, justicia y libertad?", América Latina hoy, n.o 10 (junio 1995). 
adaptarse todos aquellos que pretendieran ser tratados como tales, renunciando a aquellos que los hacía diferentes.

El desafío hoy consiste en redefinir ese concepto tomando en consideración para ello el criterio de diversidad, de variedad, de diferencia (10). Pero la pregunta que surge inmediatamente es la siguiente: ¿hasta dónde se puede aceptar la diferencia sin que ello actúe en desmedro de la convivencia colectiva?, ¿cómo asegurar a un tiempo la protección a la identidad cultural y la posibilidad de elección de los individuos?, más aún ien qué condiciones la medida humana básica podrá seguir siendo la individual?, ¿qué lugar ha de ocupar la libertad individual frente a las identidades grupales? En todo caso estamos ante la construcción de un nuevo marco de convivencia basado en la idea de diversidad de la acción y del deseo humanos. En ese proceso de ingeniería sociológica en el que se trata de establecer los límites de resistencia de la convivencia colectiva ante los requerimientos de la diferencia, la variabilidad humana es el objeto central de análisis y en este contexto el conocimiento socio-histórico está llamado a jugar un papel importante.

Habida cuenta de que disponemos ya de una respuesta provisional sobre las exigencias sociales a las que debería adecuarse el conocimiento histórico si pretende ser un saber socialmente útil, cabe preguntarse por la segunda parte del dilema, ¿de qué manera, desde qué perspectiva, el pasado y su conocimiento puede contribuir a mejorar nuestra destreza para construir nuevos modelos de convivencia colectiva?

Un par de décadas atrás pocos hubiesen dudado ante esta pregunta. Se tenía la certeza, en cierta medida proporcional al grado de determinismo, de que la realidad social podía ser considerada como un todo en evolución sujeto a regularidades susceptibles de ser conocidas y anticipadas y, en ese contexto, el conocimiento socio-histórico era la forma de comprender el presente como requisito para cualquier proyección hacia el futuro. El determinismo como filosofía inspiradora de las más

(10) Puede consultarse la voz citizenship elaborada por Chantal Mouffe en Joel KRIEger (ed.), The Oxford Companion to the Politics of the World, 1993, Oxford University Press.

R. I., 1996, n.o 207 
importantes corrientes historiográficas de este siglo creyó poder, también, controlar y prever el deseo y el destino humanos. En las sociedades industriales el hombre social, históricamente condicionado, era un ser definido fundamentalmente a través de su identidad medular relacionada con el lugar que ocupaba en el proceso de producción. En esa identidad residía su miseria y su grandeza. En ella el origen de la explotación y, al mismo tiempo, el germen de su liberación. Pero, de la misma manera que su explotación era el resultado de una compleja red de factores que escapaban a su voluntad, su liberación que también le era ajena, en muchos aspectos -dada la inevitabilidad del proceso-, tenía una clara y única direccionalidad. Ante la homogeneización cultural que imponía a su paso el capitalismo la utopía socialista se presentaba, también, como un modelo de sociedad universal (11). En términos generales todo parecía bastante sencillo. Partiendo de un modelo de futuro universal, de un modelo social definido y de un sujeto del que se creía saber cuáles eran -y debían de ser- sus aspiraciones y deseos, el conocimiento socio-histórico se presentaba como una suerte de «guía para la acción».

Así, y según las previsiones de algunas formas de determinismo histórico, los últimos años del siglo nos deberían haber encontrado en plena euforia liberadora y no en esta confusión que parece prosperar cada día. La explosión de identidades en este fin de milenio ha cuestionado seriamente esa idea de identidad medular y con ella el proyecto de utopía universal. La aparición de nuevos sujetos sociales que ya no se definen en términos de clase sino por otras formas de pertenencia: sexual, étnica, religiosa, han multiplicado las posibilidades de futuro y las del presente al tiempo que ha complejizado sobremanera la situación. Interesa tanto lo que de común hay en todos nosotros como aquello que nos hace diferentes o que queremos sea tenido como parte de nuestra diferencia. En ciencias sociales el control del comportamiento humano

(11) Es cierto que en la literatura socialista aparece con frecuencia el problema de las particularidades nacionales o locales pero en lo que se refiere a la práctica del socialismo real esas particularidades parecían referirse más a rasgos pintorescos que a aspectos importantes o esenciales en la construcción social. 
-como exigencia para la construcción de la utopía universalparece haber dominado en buena parte de este siglo.

Ahora bien, la multiplicidad de identidades y la aparición de nuevos sujetos sociales con nuevas demandas han impuesto nuevas exigencias al conocimiento socio-histórico, pero no menos importante han sido, en la gestación de la crisis, el cuestinamiento de ciertos paradigmas en ciencias naturales (12) -en los que las ciencias sociales se habían amparado buscando criterios de validez y verdad (13) - con su correlato en estas últimas y el colapso del modelo alternativo del socialismo real (14).

La caída del muro y el no muy honroso final de los regímenes del Este de Europa han liquidado un tipo de modelo posible de organización social, que se basaba fundamentalmente en una idea cuasi teológica -además de teleológica- del desarrollo histórico impulsado por el progreso -concebido como independiente de la acción de los sujetos- y en el que el hombre era una pieza más del engranaje, obligado a seguir el inevitable decurso de la historia. No obstante, el fracaso de ese modelo no sólo no significa el fin de toda posible utopía, sino que en modo alguno glorifica -haciéndola pasar por la mejor posible porque es la única- la situación existente. A diferencia de Hegel no todo lo real es racional o al menos deseable. Del fracaso de un modelo de sociedad no se desprende la imposibilidad de construir alternativas, a condición de que las futuras tengan en cuenta, entre otras cosas, el carácter indeterminado, en última instancia, de la acción y del deseo humanos, su variedad y variabilidad irreductible en muchos aspectos, etc., como condiciones impuestas por los propios suje-

(12) Puede consultarse Ilya PRIGogine, «¿El fin de la ciencia?», en Dora FRIED SCHNITMAN, Nuevos paradigmas, cultura y subjetividad, Buenos Aires, Paidós, 1994 y, desde una perspectiva más general, Gerald BAKKER y Len CLARK, La explicación. Una introducción a la filosofía de la Ciencia, Madrid, Fondo de Cultura Económica, 1994.

(13) Idem, y C. Ulises Moulines (ed.), Enciclopedia Iberoamericana de Filosofía, vol. 4: La ciencia: estructura y desarrollo, Madrid, Trotta, 1993.

(14) Creo que es innegable que la caída del muro de Berlín supuso no sólo el final de los regímenes del socialismo real sino también una forma de comprender lo humano y su devenir sin que ello suponga, necesariamente, el fin de las utopías colectivistas y sin que signifique la glorificación del sistema capitalista. Una interpretación distinta de los hechos en Joseph FONTANA, La historia después del fin de la historia, Barcelona, Crítica, 1992, págs. 9-16.

R. I., 1996, n. ${ }^{\circ} 207$ 
tos sociales del presente. Pero si el futuro aparece tan abierto, tan indeterminado para la propia indeterminación humana, y es esa variedad de la acción la que debe recoger el conocimiento histórico ¿cómo puede construirse conocimiento alguno y cómo hacerlo desde paradigmas que han primado, por principio, la regularidad frente a la singularidad? El actual proceso de producción historiográfica y, consecuentemente, el sentido del saber histórico se mueve entre los partidarios de la indeterminación casi absoluta, a resultas de la cual ese saber quedaría disuelto y su campo de actuación reducido a «lo único», a "lo singular» sin proyección posible y los que se aferran a los paradigmas deterministas que no responden a las necesidades sociales y que de poco parecen poder servir a la construcción de utopías o alternativas futuras (15).

Pero, centonces de qué manera puede la historia y su conocimiento contribuir a las necesidades sociales, tomando en consideración que su objetivo es dar cuenta de la variedad y variabilidad humanas con la suficiente consistencia como para que ese saber no se convierta en pura caricatura, en registro de casos únicos o museo de fenómenos? En primer lugar, considerando a la acción humana, a los fenómenos sociales como procesos poliédricos, es decir, susceptibles de ser vistos desde distintas perspectivas, lo que implica de mano renunciar a la vieja lógica de las ciencias sociales (16), a aquellos paradigmas basados en explicaciones causales que parten de cierta idea esencialista de lo social; y, al mismo tiempo, lo anterior supone, necesariamente, historizar, desnaturalizar y ensanchar la idea de verdad (17). En segundo, amparándose en nuevas filosofías de

(15) Estoy siendo deliberadamente reduccionista para poder justificar mi propuesta. Dentro del neomarxismo se pueden encontrar buenos programas de investigación que intentan lidiar con el problema del sujeto y las estructuras de forma que se podría hablar de una tercera vía entre los deterministas partidarios de lógicas fuertes y los que propugnan el relativismo y la disolución, en último término, de todo conocimiento. La escuela historiográfica inglesa, con E. P. Thompson, E. Hobsbawn, o la sociología histórica estarían dentro de este marco.

(16) Tomo prestado este concepto de uno de los capítulos de la obra de James Bohman, New Philosophy of Social Science. Problems of Indeterminacy, Cambridge, Polity Press, 1994.

(17) Tzvetan Todorov, "Post-Scriptum: la verdad de las interpretaciones», Las morales de la historia, Barcelona, Paidós Básica, 1993 y Marina ARIZA, «La 
la historia (18) más interesadas en el saber histórico en tanto que conocimiento de lo posible más que conocimiento de lo acontecido. Si no existen regularidades generales, universales y transtemporales capaces de explicar el devenir humano por la propia indeterminación y variabilidad de su quehacer, de poco ha de servir el conocimiento de esas regularidades en el pasado. Mientras que los proyectos no ensayados, las soluciones no implementadas en la medida en que no se materializaron pueden ser aún indicios para los problemas contemporáneos. Como señalara Schiller, el poeta alemán tantas veces citado por el no menos famoso alemán y filósofo Ernest Bloch, «lo que nunca jamás ha sucedido en ningún lugar, eso sólo no envejece jamás», sentencia a la que Bloch añadió "lo que aún nunca jamás ha sucedido en ningún lugar, eso solo no envejece jamás».

El análisis histórico serviría, así, para descubrir posibilidades y hacerlo en coyunturas en las que la proliferación de proyectos se hace más notoria, cuales son los momentos de crisis. Gracias a esta perspectiva interesada en las utopías no materializadas, en los campos de posibilidad, se contribuiría a la construcción de un discurso socio-histórico abierto al cambio, relativo -que nada tiene que ver con el relativismo ético sino con una suerte de relativismo epistemológico- refutador de esa idea tan extendida según la cual «las cosas sucedieron de la única manera posible», reflejo del paradigma determinista. Y ese discurso relativo, abierto y esperanzador que concede un papel protagónico a los sujetos ha de ser un discurso liberador en la medida que ensancha la conciencia de los protagonis-

\footnotetext{
causalidad como lógica de las determinaciones en Ciencias Sociales", Suplementos Anthropos, n. 45 (septiembre 1994), págs. 80-85.

(18) Nuevas en la medida en que no han sido aplicadas. Puede consultarse, Hugo Zemelman, Los horizontes de la razón, Anthropos/Colegio de México, 1992 y del mismo autor, De la historia a la política, México, Siglo XXI/Universidad de las Naciones Unidas, 1989. Más reciente el número 45 (septiembre de 1994) de los Suplementos de la revista Anthropos coordinado por H. Zemelman. También puede consultarse de Walter BenJAMín su "Tesis de Filosofía de la historia» en Discursos interrumpidos, vol. I, Madrid, Taurus, 1987 y los trabajos publicados en la revista Anthropos, n. ${ }^{\circ}$ 146/147 sobre Ernest Bloch, así como los textos del filósofo alemán en los Suplementos de la misma revista en el número 41 de noviembre de 1993. Revisten particular interés en la antología de textos "La ontología del aún-no" y "Lo utópico en la historia».
}

\section{R. I., 1996, n.o 207}


tas, ayudándoles en la búsqueda de nuevas alternativas (19), porque la primera condición para que algo sea posible es que sea concebido, pensado como tal, en su posibilidad.

En suma, la crisis de sentido en historiografía que parece querer convertir al saber histórico en un conocimiento fútil guarda relación con una serie de sucesos de orden político y con otros de naturaleza epistemológica. Precisamente porque la visión del futuro ha cambiado -de esa concepción única y universal a esta otra plural y variada- también lo ha hecho la semántica de los tiempos a decir de Koselleck (20), la noción del presente y la del pasado y con ello la utilidad que el conocimiento del pasado puede proporcionar a la reconstrucción del futuro. Pero no debemos confundirnos, cierta función social del saber ha hecho crisis, no toda posible función del conocimiento social. En este sentido, dos son los criterios de pertenencia que se desprenden de las notas anteriores: diversidad y variabilidad de la acción humana y la búsqueda de la potencialidad, de la posibilidad en las acciones o sucesos del pasado.

\section{LA PROPUESTA: CONCIENCIA Y POSIBILIDAD}

Diversidad-variabilidad como objetivo del análisis histórico porque de lo que se trata, de acuerdo con los nuevos tiempos, es de comprender y aprehender la riqueza de lo humano contenida en lo social, sus cambios y movimientos, sus contextos de inteligibilidad, sus referentes macro y micro. Posibilidad - entendida como la opción contenida en el pasado pero no materializada, esas otras alternativas presentes en cada coyuntura de las que hablaba Braudel- como requisito de apertura hacia lo nuevo, porque la crisis de las determinaciones ha puesto en entredicho la utilidad de un saber construido sobre lo acontecido e irrepetible.

(19) H. Zemelman señala que no se trata de un voluntarismo irracional. Véase Hugo ZEMELMAN, "Racionalidad y Ciencias Sociales» en Suplementos Anthropos, n.o 45 (septiembre, 1994), págs. 5-22.

(20) Véase Reinhart Koselleck, Futuro pasado. Para una semántica de los tiempos históricos, Barcelona, Paidós, 1993. 
Pero vayamos por partes. La diversidad-variabilidad se impone como criterio necesario ante la necesidad de buscar y encontrar un nuevo marco de convivencia colectiva -entendido como principio rector y aglutinador- que respete o integre las diferencias de los nuevos sujetos sociales y de nuevas subjetividades. A diferencia de los programas inspirados en la lógica determinista el objetivo del conocimiento no es descubrir los mecanismos que permitan construir ese futuro común $\mathrm{y}$ homogéneo dibujado por la utopía y no porque las utopías -ahora variadas y múltiples- no sean posibles sino porque nos encontramos en un momento previo, el del reconocimiento de la propia identidad, de apertura hacia la consciencia, de rastreo del propio deseo, de las expectativas de esos nuevos sujetos colectivos, de construcción de nuevas identidades. Paso previo o simultáneo al de la formalización de nuevos horizontes utópicos, nuevas alternativas grupales y colectivas. Pero, ¿en qué medida pueden los análisis del pasado contribuir a esos propósitos? Más allá de la búsqueda de los orígenes o del desarrollo lineal de esas identidades, el conocimiento sociohistórico tiene capacidad reflexiva para enfrentar a los sujetos con la relatividad, historicidad de su propio deseo, de sus expectativas y aspiraciones. La historia es, en este sentido, un perfecto instrumento de desnaturalización de la propia identidad, siendo éste el camino adecuado para alcanzar una mayor consciencia de sí.

Diversidad de la acción social que convierte en inadecuado el marco de análisis de la historiografía determinista, tan preocupada por la regularidad. La diversidad actual exige nuevas lectura del pasado mediante la descomposición de conceptos, categorías grupales en otros nuevos, en otras perspectivas que contribuyan a soldar la fractura entre conocimiento y sociedad. Diversidad no significa, no obstante, excluir la idea de regularidad y apostar por lo individual e irrepetible. No es ese el propósito. No es ésta una propuesta ni en favor del individualismo - "cada individuo es un mundo»-, del empirismo pueril -«como no hay posibilidad de repetición en la historia a lo único que se puede aspirar es al relato de acontecimientos únicos»-, ni en pro de una vuelta a la historia de los grandes hombres -como señalara Pascal iqué hubiera pasado si la nariz de Cleopatra hubiese sido más corta?-. 
Antes bien, lo que creo que conviene hacer es incorporar el concepto de indeterminación y, entonces, sólo entonces, intentar adecuarlo y no proceder a su destierro. Ello supone violentar constantemente las categorías con las que trabajamos, violentar y cuestionar los conceptos, las estratificaciones del objeto de análisis. Significa también abrirse a la riqueza de lo social mediante una utilización de la teoría, de las grandes teorías que ordenan la realidad humana a la baja para permitir que lo nuevo, lo diferente, lo que escapa a la regla pueda ser introducido y también supone reconsiderar nuestras formas de razonamiento para acompasarlos a esa diversidad en última instancia indeterminada. Casi nadie duda de la existencia de algunos fenómenos sociales de carácter universal, algunos impulsos humanos de naturaleza transcultural, el problema es si son capaces de explicar la diversidad y, más aún si su existencia y su conocimiento puede contribuir en modo alguno a los retos de este fin de siglo.

De la ruptura de esa secuencia futuro-pasado-presente, según la cual la apuesta por un modelo de futuro condicionaba y dictaba la apertura hacia el pasado que debía servir para guiar las acciones de ese presente-futuro, se deduce que se ha perdido el mítico hilo de Ariadna para salir del laberinto o, más aún que no fue sólo el hilo el que le permitió a Teseo, después de matar al Minotauro, encontrar la salida sino una corona que iluminaba los rincones oscuros del palacio. Todo parece sugerir que puede haber más de un camino para salir del dédalo y que esos itinerarios se van modelando y configurando al desandar el laberinto. Aún más, todo hace pensar que los Teseos recluidos tienen distintos proyectos e incluso distintas percepciones de lo que es la liberación y el final del viaje. Por ello, porque la diversidad se presenta como una condición del conocimiento útil, la nueva historiografía debe violentar las categorías de análisis tal y cómo lo está haciendo al combinar viejas nociones -como la de clase- con otras nuevas que, a veces priman lo individual -como en el caso de la microhistoria-, otras lo grupal en términos de género o de inclusión y exclusión social -como el caso de la historia de los pobres, de los marginados-, o al analizar aspectos de las distintas subjetividades sociales -la historia de la sexualidad o de la vida cotidiana-. 
Violentar nuestros instrumentos de análisis -lo que implica cambiar nuestra forma de ver el objeto de estudio- se convierte, así en una condición de partida, pero, ¿cómo hacerlo?, ¿desde dónde? Algunos programas deterministas apelan a una meta discurso científico verdadero que determina la oportunidad de ciertos conceptos o categorías. El problema es que esta propuesta pretende alejarse de esa lógica dualista, entonces idesde dónde o en relación con qué criterio debemos proceder a la construcción y deconstrucción de conceptos, y categorías -gracias a los cuales reinterpretar el pasado- que contribuyan a la desnaturalización y relativización de las nuevas identidades sociales? Desde nuestras necesidades y a través de la interpretación de la realidad social hecha por los sujetos sociales del pasado. Es su propia subjetividad la que se ha convertido en objeto de análisis y ello no sólo porque se parte de la premisa de que la realidad social está constituida por las significaciones que los actores dan a sus acciones o porque se considere que la acción humana es inteligible a través del sentido, sino también porque es ésta una condición de utilidad del conocimiento tal y como aquí se propone. Si uno de los objetivos señalados para el conocimiento socio-histórico era desnaturalizar las identidades de los nuevos sujetos sociales al historizarlas, servir de vigilancia en la construcción de su propio deseo, interesa aprehender esas subjetividades sociales contra todos sus contextos o referentes posibles aún a sabiendas de que ese conocimiento será siempre incompleto y parcial. Las herramientas conceptuales de la nueva historiografía, ellas mismas en constante revisión, se nutrirán de la subjetividad, de las definiciones, de las interpretaciones de los propios sujetos en el pasado, lo que no significa que ahí acabe su cometido o que se confunda las subjetividades históricas con el análisis histórico.

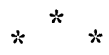

Con demasiada frecuencia la historiografía ha despreciado el estudio de las subjetividades sociales bien porque las consideraba terreno pantanoso, porque estaba más preocupada por las práctica o la conducta de los agentes o simplemente porque las consideraba como reflejo de otros niveles de la realidad so- 
cial. Lo cierto es que la diversidad humana y social a la que hoy hemos de hacer frente reclama cierta inteligibilidad, cierto orden -en términos de operatividad política y ética- y poco se sabe -más allá de los análisis individuales genético-familiaresde cómo se forman y construyen esas entidades, cuáles son sus referentes o contextos -isingulares, múltiples?- contra las que ordenarlas o leerlas, preocupados como estábamos por la unidad del comportamiento y la acción (21).

Ahora bien, utilizar las subjetividades sociales como material para la construcción de nuevas categorías o de un nuevo y cambiante bagaje conceptual no significa confundir lo primero con lo segundo, pero tampoco significa contraponerlo. Introducirnos en las apreciaciones de los sujetos del pasado entreabre la posibilidad de acceder a una riqueza -diversidadvariabilidad- que difícilmente podríamos aprehender desde la mera objetivización de los acontecimientos. Pero la construcción del saber histórico no puede descansar sólo en las interpretaciones de los agentes del pasado, sino también en un diálogo abierto con las generaciones del presente. Entre otras razones porque en un determinado momento histórico los sujetos se encuentran en el umbral de distintas posibilidades -algunas previstas, otras no- y su conocimiento es, necesariamente, incompleto y parcial. Desde el presente, los análisis del pasado permiten captar -en la medida que se han cerrado algunos ciclos- posibilidades no vistas como tales por los contemporáneos aún a sabiendas que también este conocimiento ha de ser parcial e incompleto.

Es precisamente ese carácter incompleto del conocimiento socio-histórico, con la figura gráfica de un diálogo entre distintas generaciones del pasado y del presente, lo que lo puede convertir en un saber socialmente útil. Si partimos de la premisa de que esta acción humana no está totalmente determinada por leyes generales externas a los sujetos -lo que no significa que no está condicionada aunque sólo sea por la existencia de "otros» agentes- ¿de qué sirven los análisis del pasado que buscan captar esas regularidades generales con capaci-

(21) El profesor H. Zemelman en El Colegio de México y junto a otras instituciones ha iniciado una investigación sobre las nuevas subjetividades sociales. 
dad predictiva o, si se prefiere tendencial? Dicho de otro modo si lo pasado está muerto y representa, en muchos casos, ciclos cerrados, ¿para qué su estudio? Se podría contestar que para poder recorrer la distancia entre pasado y presente. Esto es, la constatación de un suceso contemporáneo requiere de la búsqueda de sus orígenes. Pero cuando se habla de la utilidad social del saber histórico se tiene más ambición que la que proporciona esta historia-génesis o historia-crónica. Reformulando la pregunta, ¿qué historia puede convertirse en un conocimiento útil? La historia posible, los análisis que intentan dar cuenta del pasado no sólo en tanto «que fue» sino del pasado en términos de posibilidad. Así se abre un diálogo en el que el pasado necesita del presente, de la interpretación historiográfica para realizarse, para desarrollarse y, más importante aún, el presente, los sujetos del presente con sus preguntas abiertas se encaminan al pasado no para captar lo irrepetible sino para aprehender lo posible. De esta manera se entabla entre el pasado y el presente un puente útil y necesario, un depósito en el que los sujetos del presente acuden para buscar respuestas a sus preguntas, pero no respuestas sobre lo acontecido, lo cerrado, sino sobre lo posible, lo abierto, lo indeterminado.

Porque el cometido impuesto por esta nueva forma de concebir el conocimiento socio-histórico no puede reducirse a ser instrumento de relativización o historización de la realidad social y de las aspiraciones de los nuevos sujetos sociales. Si concebimos el pasado como una trama en la que algunas secuencias se cierran y completan y otras quedan abiertas, dibujadas, sugeridas, el pasado puede concebirse como lo acontecido y, también, como lo posible. En la idea de posibilidad -que nada tiene que ver con la historia contrafactual- está anclada la noción de intersubjetividad que puede transformar el conocimiento socio-histórico en un saber útil, lejos de la lógica determinista. Precisamente porque la acción humana es, en última instancia, indeterminada existen esos campos de posibilidad -de lo no realizado, pero realizable- a través de los cuales construir el puente de la intersubjetividad. Dicho de otro modo, porque no todo en lo referente a la realidad social pasada está determinado podemos hacer uso en el presente de esa potencialidad que requiere para hacerse realidad de la ac-

R. I., 1996, n. 207 
ción humana y de una mayor consciencia de sí. Bloch decía «las cosas nos necesitan», si la posibilidad no se concretó en el pasado no se debió, sin duda, a ningún impedimento mecánico ni teológico, sino a la acción o a la inercia de los hombres. Posibilidad entendida como lo probable que le falta la determinación humana para hacerse real, pero cuya materialización puede llevarse a cabo en el momento presente, a través de la consciencia de su posibilidad y de sus limitaciones en el pasado.

\section{LA PRÁCTICA HISTORIOGRÁFICA Y EL JUEGO DE LAS ANALOGÍAS: TÁBANOS, LECHUZAS Y COLIBRIESS}

En suma, la «nueva» historiografía con pretensiones de utilidad social debería, según esta propuesta, estar orientada hacia la diversidad-variabilidad de lo humano y de lo social y hacia la aprehensión de la posibilidad en el conocimiento del pasado. Ante la aparición de nuevos sujetos sociales en contextos muy fragmentados, la diversidad y variabilidad hacia las que ha de tender el conocimiento histórico contribuirían a la construcción crítica, a través del auto-conocimiento y la conciencia, de las nuevas identidades colectivas. Las nuevas subjetividades encontrarían así un referente sobre el que relativizar su propia constitución. Este ejercicio crítico, auto-crítico, implica la búsqueda de nuevas «topografías» sociales en el pasado, de nuevos sujetos y pertenencias, violentando categorías y conceptos, desnaturalizándolos, historizando nuestro propio lenguaje o, lo que es lo mismo, nuestra forma de ver la realidad social.

Pero para poder acceder a la diversidad y a la variabilidad se debe operar con marcos teóricos muy flexibles que no se cierren a esa posibilidad a través de la búsqueda de regularidades (22). Difícilmente se puede incorporar lo distinto, lo nuevo, lo irregular si se está empeñado en confirmar o refutar -a través de otras regularidades- un enunciado teórico con categoría de ley, regularidad o tendencia. De ahí que la deducción no siempre sea la forma de razonamiento más idónea. En cambio,

(22) H. Zemelman hace un análisis interesante de este problema en su obra [18]. 
la inferencia clínica o la abducción (23) pueden ser lógicas que proporcionen una mayor utilidad en la medida en que trabajan con conjuntos de regularidades muy contextualizadas y siempre dentro de una aproximación posible y no cierta.

Nuevas conceptualizaciones, marcos teóricos flexibles, formas de razonamiento no deductivas y unidades de análisis micro son algunas de las exigencias para la apertura hacia la diversidad-variabilidad de lo social. En este contexto lo micro, los análisis individuales que hace la microhistoria por poner un ejemplo, no significa un fin en sí mismo ni tiene que ver con afanes coleccionistas. Lo micro se convierte en necesario para comprender toda la diversidad humana hasta donde seamos capaces de llevar nuestro análisis. Un tratado de la diversidad social y humana requiere de estos análisis de "grano fino" que nada tienen que ver con la historia evenementillé o con el empirismo pueril. Lo micro como unidad de análisis es necesario, pero también lo son los niveles macro, sin que se produzca contradicción alguna. La elección de la unidad dependerá del problema a tratar y no de la teoría elegida.

De esta forma y mediante estas sugerencias sobre las prácticas historiográficas el conocimiento histórico puede contribuir en la construcción crítica de las nuevas subjetividades sociales y convertirse así en un saber socialmente útil y en un instrumento de historización y desnaturalización de las demandas de los nuevos sujetos. Hay que recuperar para las ciencias sociales $\mathrm{y}$, en concreto, para la historia la idea socrática de tábano, metáfora de la función del filósofo en la polis: «atado por el Dios al costado de la Ciudad como al costado del caballo poderoso y de buena raza, pero al que su propia fuerza da demasiada pesadez y que tiene necesidad de ser despertado por una especie de tábano» (24).

Pero no era la capacidad reflexiva la única propuesta; también reconocimos la potencialidad contenida en el pasado y

(23) El concepto de «inferencia clínica» ha sido utilizado por diversos autores. Un desarrollo del mismo en Clifford GeERTZ, "Descripción densa: hacia una teoria interpretativa de la cultura», La interpretación de las culturas, Barcelona, Gedisa, 1992, pág. 36. Para el concepto de abducción en historiografía, puede consultarse a Carlo GinzBURG, El queso y los gusanos, Barcelona, Muchnik, 1981 y, desde una postura crítica, J. ARostegui, [2].

(24) Citado en T. Todorov [17].

R. I., 1996, n.० 207 
que permitía la constitución de una nueva intersubjetividad, un nuevo diálogo entre el presente y el pasado. Lo acontecido no es lo único que ha de interesar al análisis historiográfico, lo posible -entendido como lo «aún no consciente» o lo «aún no acontecido" a la manera blochiana- también entra en su campo de estudio. Lo posible es lo que convierte al pasado en depósito de sugerencias, en banco de respuestas para las actuales preguntas. Esto no supone que sólo deba estudiarse lo posible, entre otras cosas porque lo potencial está íntimamente relacionado con lo acontecido, pero sí que el análisis de lo ocurrido debe de estar supeditado a la búsqueda de la potencialidad.

No deja de resultar paradójico que este "voluntarismo racional» invierta nuestra concepción lineal del tiempo y busque en "lo no acontencido" del pasado la inspiración para la construcción de «lo que puede acontecer» en este presente-futuro. Todo parece indicar que los nuevos tiempos reclaman nuevas analogías y, así, la lechuza de Minerva, que levantaba su vuelo al ponerse el sol ha de ser sustituida por el colibrí multicolor que con su frenética actividad al rayar el alba anticipa lo que será (25).

The crisis in the social sciences has effected our socio-historical knowledge, making it meaningless. In reaction to this situation, new and diverse forms of historical research have emerged. Each of them intends to be a step forward in the direction of a far-reaching, new proposal which, on the basis of a particular interpretation of the crisis, aims at endowing historical konwledge with a renovated critical capacity.

(25) La analogía del colibrí la tomo prestada del filósofo Cerutti-Guldberg quien en una excelente intervención en el encuentro «Pensamiento y Cultura en la Universidad" que tuvo lugar en México en diciembre de 1995 la propuso como nuevo símbolo de la filosofía lationoamericana. 